\title{
Increasing client participation in family planning consultations: "Smart Patient" coaching in Indonesia
}

Young Mi Ki

Fitri Putjuk

Endang Basuki

Adrienne Kols

Follow this and additional works at: https://knowledgecommons.popcouncil.org/departments_sbsr-rh

Part of the Demography, Population, and Ecology Commons, International Public Health Commons, Public Health Education and Promotion Commons, and the Women's Health Commons How does access to this work benefit you? Let us know!

\section{Recommended Citation}

Ki, Young Mi, Fitri Putjuk, Endang Basuki, and Adrienne Kols. 2002. "Increasing client participation in family planning consultations: 'Smart Patient' coaching in Indonesia," FRONTIERS Final Report. Washington, DC: Population Council. 


\title{
INCREASING CLIENT PARTICIPATION IN FAMILY PLANNING CONSULTATIONS: "SMART PATIENT" COACHING IN INDONESIA
}

\author{
Young Mi Ki \\ Fitri Putjuk \\ Endang Basuki \\ Adrienne Kols
}

Johns Hopkins University Center for Communication Programs

\footnotetext{
"Operations Research: Impact of Client Communication Training on Client Participation and Contraceptive Continuation in Indonesia." This study was funded by the U.S. AGENCY FOR INTERNATIONAL DEVELOPMENT (USAID) under the terms of Cooperative Agreement Number HRN-A-00-98-00012-00 and Population Council Subagreement number A100.68A. The opinions expressed herein are those of the author and do not necessarily reflect the view of USAID.
} 


\section{SUMMARY}

Context: Paternalistic models of health care, social distance between clients and service providers, and cultural norms discourage family planning clients from playing an active role in consultations. Interventions are needed to encourage clients to communicate more openly and more vigorously with providers.

Methods: While waiting to see a service provider, 384 family planning clients in Indonesia received individual coaching on their right to speak out and on three basic communication skills: asking questions, expressing concerns, and seeking clarification. An equal number of clients in the control group received an HIV/AIDS booklet to read while waiting. The consultations were audiotaped and analyzed, and both the educators and clients were interviewed. Home visits with clients were made eight months later to measure contraceptive continuation.

Results: Compared with clients in the control group, those who received Smart Patient coaching raised significantly more questions (6.3 vs 4.9$)$ and concerns (6.7 vs 5.4$)$ during the consultations, but they did not seek clarification or volunteer information more often. Smart Patient coaching narrowed differentials in active communication by client type, age, and assertiveness, but it widened differentials by client education and socioeconomic class. Coaching was associated with more tailored information-giving by providers $(24.9$ vs. 21.1). However, the intervention did not make a significant impact on contraceptive continuation rates at eight months.

Conclusion: Educational interventions directed to family planning clients can complement and reinforce provider Interpersonal Communication and Counseling (IPC/C) training by giving clients the confidence and the communication skills to take advantage of increased opportunities for participation. 


\section{CONTENTS}

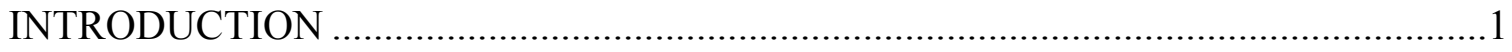



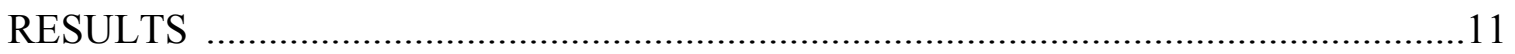

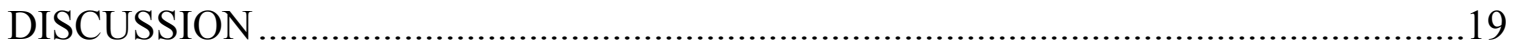

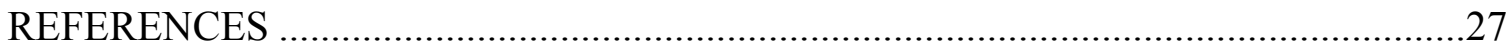

\section{Appendices: Tables and Figures}

Table 1. Percentage distribution of client characteristics by intervention and control group

Table 2. Percent of clients who have experienced psychosocial barriers to communicating with midwife in the past

Table 3. Frequency of client active communication in control and intervention groups, by selected client characteristics

Figure 1. Frequency of client participation: Smart patient intervention vs. control

Figure 2. Frequency of client questions: Smart patient intervention vs. control 


\section{ACKNOWLEDGMENTS}

This study was made possible by financial support from the U.S. Agency for International Development under Cooperative Agreement HRN-A-00-98-00012-00, through the Population Council/ FRONTIERS Small Grants Program. The authors thank Leslie B. Curtin, Molly Gingrich, Lana Dakan, Pam Wolf and Bambang Samekto (USAID/Indonesia); Sugiri Syarief, Eddy Triatmodjo, Siti Fathonah, Wahyuni, Endah Winarni, Mudjianto of the National Family Planning Coordinating Board (BKKBN); Nurfina Bachtiar, Endang Iradati, J. Douglas Storey, Gary Lewis (JHU/CCP Indonesia); Emiria Sirman, Paramita Damayanti, Yuliastini Handoyo, Linda Fitriwati, HR Soedibjo, M Sulaksmono, Izhar M. Fihir (Consultants in Indonesia); Phyllis T. Piotrow, Jane Bertrand, Anne Palmer, Michelle Heerey, Elizabeth Costenbader (JHU/CCP/Baltimore); Debra Roter and Susan Larson (JHU); and Donald Cegala (Ohio State University). 


\section{INTRODUCTION}

\section{Background}

Family planning and health care clients can improve the quality of care by actively communicating with doctors, nurses, and other providers. Research shows that when clients fully disclose their concerns, expectations and preferences, providers can assess their problems more accurately and offer better advice. ${ }^{1}$ Similarly, when clients request information from providers, they make better informed decisions, feel more control over those decisions, and are more committed to implementing them. ${ }^{2}$ When clients check their understanding of instructions, they are better able to recall them and more likely to take action. $^{3}$

Ultimately, this type of active participation by patients improves health outcomes: U.S. and European studies have linked patient participation with alleviation of symptoms, improved patient functioning, and increased adherence to treatment plans. ${ }^{4}$ While less data is available on family planning outcomes, active participation in consultations may help clients choose an appropriate contraceptive method, use it effectively, monitor and cope with side effects, and return for check-ups and resupply as needed. ${ }^{5}$

Yet studies have found that health care and family planning clients in both developed and developing countries generally participate little in consultations: they rarely express all of their concerns, ask few questions, keep their responses brief, and seldom clarify information. ${ }^{6}$ When they do participate, clients may use passive strategies to achieve their goals, for example, waiting for cues from service providers before speaking or mentioning a neighbor's experience rather than asking a direct question. ${ }^{7}$ 
The lack of active client communication leads to misunderstandings between clients and providers which, in turn, cause poor outcomes. ${ }^{8}$

Several barriers discourage clients from actively participating in family planning and health care consultations. In the conventional model of medical care, doctors play an authoritarian role and assume total control of the consultation; patients are supposed to be

passive. $^{9}$ Reinforcing this highly unequal relationship are socioeconomic and educational disparities that create social distance between clients and providers. ${ }^{10}$ In Asian countries, cultural norms emphasizing conflict avoidance and respect for people of higher status also may make client participation socially inappropriate. ${ }^{11}$

\section{Empowering Client Communication}

Many interventions have tried to improve the quality of the client-provider interaction, generally by training providers in interpersonal communication and counseling (IPC/C) skills. In Indonesia, for example, the State Ministry of Population/ National Family Planning Coordinating Board (BKKBN) developed a curriculum on interpersonal communication and counseling (IPC/C) skills for nurse-midwives and nurses working at local clinics (puskesmas). Part of the curriculum discussed how providers could encourage client participation. Providers in East Java and Lampung provinces attended refresher workshops on IPC/C in 1998 and 1999, and some also participated in selfassessment and peer review activities to reinforce that training. This training and reinforcement program markedly improved provider communication but had a more limited impact on client behavior. ${ }^{12}$ 
Some researchers in developed countries have taken a more direct approach to changing client behavior, using patient education to increase participation during health care visits. Most of these interventions have been conducted in the waiting room immediately before patients see a physician. Patients have been given print materials to read, ${ }^{13}$ videotapes or computer programs to view, ${ }^{14}$ or individual coaching by a patient educator. ${ }^{15} \mathrm{~A}$ few interventions have reached patients at home or in the community with print materials, ${ }^{16}$ telephoned instructions, ${ }^{17}$ or group educational programs. ${ }^{18}$ For the most part, these efforts at patient education have focused on teaching patients specific communication skills, such as how to ask questions, disclose information about symptoms and medical concerns, and check understanding of the diagnosis and treatment plan. Legitimizing patients' right to speak also has been a key component of some interventions. $^{19}$

The results of these studies have been largely, although not entirely, positive. ${ }^{20}$ In some studies, brief training of patients in communication skills before they see a provider has helped them ask more questions, ${ }^{21}$ disclose more information about their health problems, ${ }^{22}$ elicit more factual information from providers, ${ }^{23}$ and recall treatment plans more accurately. ${ }^{24}$ Other studies have found no impact on question asking ${ }^{25}$ or recall of treatment plans. ${ }^{26}$ The impact on patient satisfaction and anxiety levels has been inconsistent.

Given the success of patient education in developed countries, BKKBN decided to test a similar intervention in Indonesia. Planners decided on a waiting room intervention, in part, to take advantage of client waiting time at clinics and, in part, to maximize the impact of the intervention by reaching clients immediately before they saw 
a provider. Individual client coaching was used to overcome potential literacy problems posed by print materials and to allow the intervention to be tailored to individual client needs. The content of this "Smart Patient" intervention was based on prior research into client-provider communication in Indonesia, which suggested the importance of giving clients explicit permission to speak out and of coaching them on how to ask questions, express concerns, and request clarification. ${ }^{27}$ 


\section{Study Objectives}

The present study tests the impact of Smart Patient coaching on client participation and provider communication during family planning counseling sessions in Indonesia. Specific research questions include:

- Does coaching increase clients' belief that they can and should speak out?

- Does coaching increase the number of questions asked, concerns expressed, and requests for clarification made by clients?

- Does coaching affect some clients more than others, depending on their age, education, assertiveness or other characteristics?

- Does coaching have an indirect effect on providers, increasing the amount of tailored information they give clients?

- Does coaching contribute to method continuation at eight months?

\section{METHODS}

\section{Research Design}

The study was conducted in 64 clinics in two districts of East Java Province (Jombang and Mojokerto), which have a similar socioeconomic make up and are roughly the same distance from the provincial capital of Surabaya. The clinics were randomly selected from those that participated in a previous study of IPC/C training and reinforcement. ${ }^{28}$ One provider per clinic was invited to participate. In most cases, they were the only provider at the clinic who concentrated on family planning services. Where there was more than one family planning provider at a clinic, one was randomly chosen to 
participate. All of the providers had received five days of IPC/C training about two years before this study.

The study employed an experimental design with randomized intervention and control groups. Twelve family planning clients per provider, including 4 new and 8 continuing clients, were asked to participate in the study, and they were evenly divided between the intervention and control conditions. Thus about 768 randomly selected clients participated in the study: 128 new clients in the intervention condition, 128 new clients in the control condition, 256 continuing clients in the intervention condition, and 256 continuing clients in the control condition. In half of the clinics, researchers randomly selected 2 new and 4 continuing clients for the intervention condition over the first two days of field work; in the following two days, they recruited an equal number of

clients to the control condition. In the remaining clinics, this order was reversed, with the control condition preceding the intervention. This design eliminates the district, clinic, and provider as a source of variation. Data analysis found no significant differences in results depending on whether the intervention preceded or followed the control condition.

\section{Smart Patient Coaching and Data Collection}

A client educator and research assistant were assigned to each cluster of 5 or 6 clinics to conduct the intervention and collect the data. Client educators were BKKBN supervisors of community-based workers, while the research assistants were recent graduates from a local university. Client educators received one day's training on how to coach clients and complete one portion of the questionnaire, followed by one day's practice at a clinic.

Research assistants received two days training on the intervention, interview techniques, 
and the questionnaire.

Before any data collection or interventions took place, the research assistants asked participating providers and clients for permission using consent forms. There were no refusals. Once providers agreed to participate, the research assistant briefly interviewed them about their work experience as well as their attitudes toward client participation. After clients agreed to participate, research assistants interviewed them about the purpose of their visit, their family planning history, and their attitudes toward client participation.

Clients in the intervention condition then met individually with a client educator, either in a separate room or in a private area of the waiting room. The educator led the client through a series of highly structured exercises using the Smart Patient leaflet and a second leaflet listing common questions and concerns related to specific family planning methods. The educator began by explaining the purpose of the training, reviewing the reason for the client's visit to the clinic, and discussing the client's anxieties about talking with a provider. The educator told clients they had the right to ask questions and reminded them that "The nurse is waiting to hear from you." Then the educator helped the client formulate and write down specific questions for the provider. Clients rehearsed each question aloud, with the educator giving appropriate feedback. The educator then helped the client formulate, write down, and rehearse specific concerns and worries. After that, the educator discussed how to ask the provider for clarification if the client did not understand something during the consultation. Finally, the educator encouraged the client to apply all these new skills during the counseling session.

Clients in the control condition were given a leaflet on HIV/AIDS to read in lieu 
of Smart Patient education. The educator remained with the client for about 15 minutes while she read the leaflet and answered any questions the client had, but did not actively educate them on HIV/AIDS.

When the client met with the provider, the research assistant audiotaped the consultation in the least disruptive way possible. Although providers were aware that some clients were receiving an educational intervention, providers did not know the content of the intervention or which clients received it. To ensure that providers remained blind to the content of the intervention and the intervention status of the client, clients did not take the leaflets or the written lists of questions and concerns into the counseling sessions with them. Immediately after the consultation, the research assistant interviewed the client about her participation in and satisfaction with the session and recommended referrals or follow-up appointments. Clients in the intervention group also were asked to evaluate the Smart Patient intervention.

Additional information on Smart Patient coaching comes from observations of client education sessions, observations of consultations, and in-depth interviews and focus group discussions with clients, providers, and client educators. This qualitative information was used to assess the implementation process and explain findings from the quantitative data collected.

Data on contraceptive continuation rates was collected eight months after the initial intervention. Clients were asked for their consent to a follow-up visit at home when they first agreed to participate in the study. Educators were able to locate and interview 745 of the 768 clients. During the follow-up visit, the educators asked the women what contraceptive method, if any, they used during each of the preceding eight 
months and noted any changes in method use. If the woman was not using a method at the time of the follow-up visit, she was asked why.

\section{Analysis of Audiotapes}

Two different coding systems were used to analyze the content of the audiotaped consultations: the Roter Interaction Analysis system (RIAS) and client communication codes developed by Cegala and colleagues. Indonesian coders who understand the local language were specially trained to use each coding system. They used a computerized data entry screen to assign codes to each utterance as they listened to the audiotapes. They listened to each tape twice, coding each system separately.

The RIAS system, which has been used extensively in both developed and developing countries, assigns one of about 40 mutually exclusive codes to every utterance made by a client or provider during the course of a consultation. ${ }^{29}$ An utterance is a complete thought, usually a phrase or sentence. The adaptation of RIAS used here was developed for a previous study conducted in Indonesia. ${ }^{30}$

For the purposes of analysis, RIAS codes of special interest were combined into larger categories to form three key dependent variables:

- Client active communication allows clients to play an active role in and guide the direction of the consultation. It includes codes for asking questions, seeking clarification, expressing concern, seeking reassurance, stating an opinion, expressing approval or disapproval, requesting services, and making personal/social remarks. 
- Provider tailored communication consists of information and advice related to the client's personal needs and circumstances. It includes codes for giving personalized family planning information, giving lifestyle and psychosocial information, and counseling on medical, family planning, lifestyle and psychosocial issues.

- Provider technical information giving consists of generic information on family planning and biomedical issues that is not related to the client's personal situation. It includes codes for giving medical, family planning, and routine information. A portion of the coding system developed by Cegala and colleagues ${ }^{31}$ also was employed, because it takes a broader view of eliciting and providing information than RIAS. Information seeking is divided into three categories.

- Direct questions are phrased in standard interrogative form ("Does the IUD cause pain?”).

- Embedded questions are phrased in declarative form but explicitly express a desire for information (“Another thing I want to ask, I've been having pain since I began using the IUD").

- Assertion questions are indirect attempts to elicit information ("Since my neighbor began using the IUD, she has had a lot of pain").

This coding system also recognizes three types of information provided by clients, depending on how much initiative they have taken.

- Solicited information includes direct, but minimal, answers to providers' questions. 
- Elaborated information also comes in response to a provider's question, but it goes beyond what is directly asked.

- Unsolicited information is volunteered by the client without prompting by the provider.

\section{RESULTS}

\section{Client Characteristics}

There were no significant differences in clients' sociodemographic characteristics between the intervention and control groups (Table 1). All were married women, 72 percent were under age 35, and over 98 percent were Moslem and Javanese. Virtually all of the women had children, and half (49\%) were currently breast-feeding a baby. Their educational level varied widely, with just over half (56\%) having completed at least junior high school. To measure clients' socioeconomic status, monthly expenses per family member were calculated. This also varied widely, ranging from 4,000Rp to $375,000 \mathrm{Rp}$, with an average of $72,000 \mathrm{Rp} .{ }^{*}$

The intervention and control groups had comparable scores on an instrument measuring assertiveness (Table 1). To assess assertiveness, clients were asked how comfortable they felt in seven potentially difficult social situations, for example, asking for the return of borrowed items.

One-third of the women were new family planning clients who came to the clinic to adopt a method, although most had prior experience with family planning and were restarting a method after having a baby (Table 1). Two-thirds of the women were continuing clients who, for the most part, came to the clinic for check-ups and resupply. 
The injectable, pill, and IUD were the methods most commonly used. More than threefourths $(77 \%)$ of continuing clients reported having a problem with their method, generally menstrual changes and headaches. Of all the women, both new and continuing clients, most (72\%) had a particular question or worry to share with the provider that day.

Both the clinic and provider were familiar to most women: 91 percent had been to the clinic before, 85 percent had been served by the provider before, and 22 percent knew the provider in a personal context, through their family or neighborhood.

\section{Provider Characteristics}

In many respects providers resembled their clients: all were women, 94 percent were married, 99 percent had children, 92 percent were Moslem, and 97 per cent were Javanese. However, the providers differed from their clients on some key characteristics that would tend to create social distance between them. Compared with clients, providers were older ( $72 \%$ over age 34 ), better educated (all were nurses and $83 \%$ had pursued additional training as midwives), and from a higher socioeconomic class (monthly expenses per family member ranged from 100,000 to $750,000 \mathrm{Rp}$, with an average of 312,000 Rp, excluding three providers from unusually wealthy families). Perhaps because of their age as well as their training, the providers were more likely than clients to use long-term methods: 34 percent relied on voluntary sterilization, a method used by none of the clients, and 31 percent used the IUD, compared with 21 percent of clients.

Most providers (86\%) had at least ten years' experience offering family planning services. They were also responsible for many other health care services, so that 87 percent spent half or less of their time on family planning. Most providers (84\%) had a private practice and saw almost as many patients in that setting as at the clinic. 


\section{Barriers to Client Participation}

According to client questionnaires, poor communication skills pose the most common psychosocial barrier to communicating with the provider: 78 percent of clients reported sometimes or often forgetting to ask questions, while 66 percent found it hard to think of questions. Other barriers reflect the unequal relationship between clients and providers: more than half of clients worried that they were taking up the provider's time, that their questions were not important, that the provider would not be interested or would ignore their concern, and that it was not their place to ask (Table 2).

While 91 percent of clients agreed that family planning clients have the right to ask questions of providers, 38 percent thought it was not always the nurse-midwife's job to answer questions, and 41 percent felt the clinic was not the place to go to get answers about family planning. More than half of clients thought that it was at least a little difficult for most women to ask questions (58\%), talk about their concerns (53\%), and ask for clarification (54\%) from providers. Nearly two-thirds of clients rated their own past participation in counseling sessions as fair to poor.

Despite their reservations, however, the majority of clients reported that they themselves feel confident and comfortable in their ability to talk about their concerns with the providers (85\%), ask questions (79\%), and ask for explanations $(72 \%)$.

\section{Self-assessment of Client Communication}

During exit interviews, over 95 percent of clients in both the intervention and control groups agreed that they had had the chance to give long answers, ask questions, express concerns, and ask for clarification in their consultations. Similar proportions reported 
that they had spoken as much as they wanted and felt that they had participated about the right amount. Less than 3 percent of all clients reported having any problem understanding the nurse-midwife's words.

However, there is acknowledged room for improvement. Ninety-four percent of clients in the intervention group and 97 percent in the control group said they had other questions that they wished they had asked the provider. Also, only about half of the clients thought they had done a good to excellent job in communicating with the provider: 56 percent rated themselves as fair to poor on asking questions, 53 percent on raising concerns, and 46 percent on seeking clarification. Women in the intervention group did not rate themselves quite as highly as those in the control group (data not shown), suggesting that Smart Patient education may have made them more critical of their own performance.

\section{Impact on Client Communication}

Smart Patient coaching increased active client communication without increasing the length of the session. Clients in the intervention group made 14.8 active utterances, according to the RIAS system, compared with 11.8 for the control group $(\mathrm{p}<.01)$. They responded to the Smart Patient intervention by more often asking questions (6.3 vs. 4.9, $\mathrm{p}<.01)$ and expressing concerns $(6.7$ vs. $5.4, \mathrm{p}<.05)$, but there was no difference in seeking clarification (1.8 vs. 1.5, ns) (Figure 1). There was no significant difference in the length of sessions in the intervention and control groups (10.1 vs. 9.4 minutes). Nor was there any difference in how the conversation was divided between clients and 
providers: the client's share of the conversation in both groups was $32 \%$ of all utterances recorded.

Results from Cegala's coding system confirm the impact of Smart Patient coaching: clients in the intervention group asked 6.6 questions compared with 4.7 in the control group $(\mathrm{p}<0.001)$. There were significant differences in both direct questions ( 5.8 vs $4.1, \mathrm{p}<.01)$ and assertion questions ( 0.7 vs $0.5, \mathrm{p}<.05)$, but not in embedded questions $(0.2$ vs $0.2, \mathrm{~ns})$ (Figure 2$)$. The overwhelming majority of all client questions $(87 \%)$ were posed directly.

On average, each client formulated and wrote down 2.5 questions and 1.5 concerns to raise with the provider during the Smart Patient coaching session. Clients brought up more than 90 percent of these questions and 88 percent of these concerns during their consultations. When clients did not ask, it was usually because the subject had already been discussed or they forgot (data from exit interviews). Clients also asked some questions that they did not write down ahead of time.

By urging clients to express concerns, Smart Patient coaching may have promoted client information giving. According to Cegala's coding system, most information given by clients was solicited by the provider (65\%). However, clients volunteered one-third of all information in the form of unsolicited statements (22\%) or as elaborated responses to provider questions (15\%). There was no difference between the control and intervention groups in the frequency of unsolicited and elaborated information giving.

Smart Patient coaching narrowed differentials in active communication by age, assertiveness, and client type (Table 3). Women age 35 or older benefited more from coaching than younger women. The impact of coaching reached significance among less 
assertive, but not more assertive women. Coaching also had a significant impact on the two types of clients one might expect to have fewer questions for providers: new clients with prior experience of family planning and continuing clients without any problems to report.

In contrast, Smart Patient coaching widened differentials in active communication by education and socioeconomic status. The impact of the intervention was greater among better educated and economically better off clients, perhaps because they found it easiest to read, absorb, and apply the Smart Patient print materials. The least educated women also gained from Smart Patient coaching, but the same was not true for the poorest women.

Providers were much better off economically than clients. To explore the impact of this disparity, a further analysis divided providers into two socioeconomic groups based on family expenses. Clients participated more actively in sessions with providers from the lower of these two socioeconomic groups (whose families spent less than $300,000 \mathrm{Rp}$ monthly per family member). The frequency of active utterances was 15.3 in these sessions, versus 11.6 in sessions with providers from the upper socioeconomic group $(\mathrm{p}<.001)$. This suggests that client participation is greater when the social distance between client and provider is smaller.

According to a multiple regression analysis, Smart Patient coaching was associated with higher levels of client active communication $(\beta=.10, p<.01)$, controlling for various client and provider characteristics, including client education, age, income, assertiveness, familiarity with the provider, family planning client type and method used, 
and provider income. Provider income $(\beta=.19, \mathrm{p}<.001)$ and client education $(\beta=.12$, $\mathrm{p}<.01)$ were also significantly associated with client active communication.

\section{Provider Communication}

Although providers strongly supported the principles of client-centered counseling in interviews, many lacked confidence in their ability to implement them. Over half (56\%) agreed that "No matter how hard I try, I cannot get family planning clients to say much." About one-fifth said they could not tell whether clients were holding something back. Equal numbers believed clients forgot to tell them things and hesitated to ask questions.

Virtually all providers were strongly motivated to do as good a job as possible, but some felt that conditions at the clinic kept them from doing their best. They cited time constraints (42\%), insufficient money and supplies (38\%), and lack of understanding by other clinic staff (30\%).

When clients ask more questions and raise more concerns, providers theoretically should respond by giving them more information. Results show that Smart Patient coaching was associated with more tailored information-giving by providers ( 24.9 in the intervention group versus 21.1 in the control group, $\mathrm{p}<.01$ ) but not with more technical family planning and medical information.

\section{Impact on Contraceptive Continuation}

Eight months after the intervention, 8 percent of study participants had stopped using contraception. Discontinuation rates were higher among new than continuing clients $(12 \%$ vs. $5 \%, \mathrm{p}<.001)$. For new clients, health concerns and side effects were the leading 
reason for discontinuation $(68 \%)$. For continuing clients, wanting to become pregnant $(50 \%)$ was the most common reason given for discontinuation, followed by health concerns and side effects (18\%).

Discontinuation rates among new clients were lower in the intervention than the control group, but the difference did not achieve statistical significance (8.7\% vs. $16.1 \%$, $\mathrm{p}=.076)$. There was even less difference among continuing clients ( $4.8 \%$ vs. $6 ; 1 \%$, ns).

\section{Process Evaluation}

On average, Smart Patient coaching sessions lasted 19 minutes, and 89 percent of clients felt the length was about right. During exit interviews, virtually all clients also agreed that talking with the educator about Smart Patient was a worthwhile way to spend time in the waiting room. While clients valued every component of the intervention, they especially enjoyed the dynamic and interactive quality of the role plays. Clients credited Smart Patient coaching with giving them more confidence to speak to the nurse-midwife (99\%), helping them formulate questions (94\%), helping them decide what to tell the nursemidwife (92\%), and reminding them to ask for clarification if they were confused $(97 \%)$.

In focus group discussions and unstructured interviews, clients said they would recommend the intervention for other women and would like further education themselves. Some said they had applied Smart Patient skills in consultations with other health care providers, and some had advocated client participation to their friends. Of key importance was women's belief that Smart Patient gave them permission to ask questions of the provider. Clients also felt rewarded because providers generally took the time to respond to their questions and, in the process, often relieved their worries. The 
educators' encouragement and the rehearsal process also increased women's confidence in their ability to speak up.

Clients said the intervention was not difficult and did not feel there was a problem understanding the content of Smart Patient materials. During exit interviews, half of the women said they preferred to read and fill out the leaflet by themselves, while the rest wanted the help of a client educator. These results are consistent with observations recorded by the educators immediately after each education session: they found that about half of the women needed little or no help to read the leaflet (55\%) or write down their questions and concerns (42\%). In further discussions with researchers, the educators suggested simplifying and streamlining the intervention.

Providers were not informed about the intervention until the study was over. During interviews and discussions afterwards, however, they responded positively to the Smart Patient concept and the idea of clients asking more questions. They requested job aids and/or training so they would be better prepared to answer clients' questions. Observations of researchers confirmed the need for more training: they found that providers sometimes gave incomplete or inaccurate responses to client questions.

\section{DISCUSSION}

\section{Essential Elements of Client Coaching}

Skills training. Like most patient education interventions seeking to improve client-provider communication, the Smart Patient intervention taught clients basic communication skills. In Indonesia, as elsewhere, family planning and health care clients often lack experience in preparing questions on technical topics, seeking attention for 
personal concerns, and asking authorities to clarify information. Skills training gives women the practical tools they need to make behavioral changes and also builds women's confidence in their ability to speak out, that is, their sense of self-efficacy.

Prompting clients to formulate and write down a list of questions beforehand is the most commonly used approach to communication skills training for patients. This exercise encourages clients to think about what they want to say to the provider and to ask more and different questions. ${ }^{32}$ In Indonesia, however, the act of writing proved a distraction for many women with limited education: instead of concentrating on the content of their questions and concerns, they worried about their spelling, grammar, and handwriting. Oral communication channels (including the client educators), interactive teaching techniques (such as the role plays), and low-literacy materials may be more effective and more appropriate for this audience. Even in developed countries, modeling and skills practice have had greater impact on client communication than purely instructional interventions. ${ }^{33}$

Overcoming psychosocial barriers. There is no reason for clients to take the difficult step of speaking out unless they believe providers will respond positively and the quality of their care will improve. ${ }^{34}$ In Indonesia, past personal experience led many women to believe that providers would ignore, dismiss, or become annoyed by their questions and concerns.

Smart Patient materials tackled this barrier to participation by explicitly giving clients permission to speak, a tactic that has proven powerful in other studies. ${ }^{35}$ Clients in focus groups agreed that one of the most valuable aspects of Smart Patient coaching was that it legitimized their right to speak during family planning consultations. They 
also confirmed what other studies have suggested: conducting an intervention in the clinic reinforces its impact by conveying the message that it is officially sanctioned and that providers are open to communication. ${ }^{36}$

While important, giving clients permission to speak may not be sufficient to change their behavior. In a British study of general practitioners, print materials announcing doctors' willingness to answer questions about treatments made no impact on patient behavior - unless they were supplemented with detailed instructions on how to do so. ${ }^{37}$

Provider preparation. When providers welcome clients' questions and concerns and take time to respond, as was the case in this study, it reinforces client active participation and amplifies the impact of patient education. This study deliberately involved providers who had received prior IPC/C training and hence were likely to be receptive to client participation. ${ }^{38}$ In a US study of patient communication, when patients were trained but not doctors, the doctors were irritated by clients' attempts to speak out and rebuffed them. ${ }^{39}$

To ensure good quality care, provider preparation must extend beyond a warm response. Providers also need sufficient technical knowledge to answer clients' questions accurately and completely, and to enable informed choices. While this study did not collect quantitative data on the quality of information offered by providers, a qualitative review of the consultations found that providers sometimes gave incorrect or incomplete answers to clients' technical questions.

Ideally providers should tailor information to each client's individual needs and personal circumstances. Smart Patient coaching did increase levels of tailored 
information giving, perhaps because client questions prompted providers to discuss personal issues and concerns.

\section{Enhancing the Impact of Patient Education}

Smart Patient coaching might have been even more effective if clients had carried the leaflet and their lists of questions and concerns into the consultation. (Researchers did not allow participants in this study to do so in order to keep the providers blind to the intervention.) Clearly, such lists can serve as a useful memory aid for clients. Sharing materials with the provider might also demonstrate the providers' support for the intervention and make clients feel more comfortable. ${ }^{40}$ A British study with a small sample size found, however, that while making a list of questions increased patient communication, showing it to the provider had no further impact. ${ }^{41}$

Educators and clients felt that two of Smart Patient's three sections—on expressing concerns and asking for clarification-were repetitive and unnecessary. However, the literature suggests the problem may be that these skills were defined too narrowly. Expressing concerns touches on, but does not fully capture the broader issue of self-disclosure which has proven powerful in health care settings. This means telling providers about one's medical history, symptoms, circumstances and concerns clearly, fully, and at the beginning of the consultation to facilitate diagnosis and treatment. ${ }^{42}$ Likewise, seeking clarification should mean more than simply understanding the providers' words. Interventions in developed countries have given patients specific instructions on how to verify their understanding of what they are told and how to formulate probing and clarifying questions to resolve potential areas of confusion. ${ }^{43}$ It is 
possible, however, that these skills are too advanced and challenging for Indonesian clients.

One of the most heartening results of the Smart Patient intervention was its ability to encourage a broad range of clients to speak out. Studies have demonstrated that client characteristics, such as gender, age, education, and social class, may constrain the flow of information between client and provider. ${ }^{44}$ With Smart Patient coaching, however, older women, less assertive women, and continuing clients without a problem all participated as actively as other women. Yet Smart Patient coaching increased disparities in active participation by education and economic class. In part, this may be due to the intervention's emphasis on reading and writing, which poor and less educated women found difficult, and, in part, it may be due to the profound social distance separating poor clients from relatively well-off and well-educated providers in Indonesia. Overcoming the barriers posed by literacy (for example, by substituting picture checklists of common questions for handwritten lists) will be far easier than convincing clients from lower socioeconomic strata not to defer to nurse-midwives.

Client-provider interactions do not occur in a vacuum: the social norms and expectations of the surrounding community have an important impact on client behavior. A study of health care clients in Hawaii found lower participation rates among those with an Asian heritage, not because they were less assertive or lacked self-efficacy, but because they believed the behavior was socially inappropriate. ${ }^{45}$ While similar cultural norms have long constrained client behavior in Indonesia, the Smart Patient intervention was fielded during a time of political upheaval when ordinary citizens began to participate in demonstrations and speak out against authorities. In this period of turmoil 
and transition, Indonesian women evidently found it easier to accept the advice of Smart Patient to speak freely with providers.

\section{Scaling Up the Smart Patient Intervention}

Perhaps the most important lesson of this study is that change in customary patterns of client-provider communication is possible — a fact which both clients and providers in Indonesia have been reluctant to accept. Based on this evidence, $\mathrm{BKKBN}$ is planning to take the Smart Patient message nationwide. Because individual client education is not practical on a nationwide scale, more cost-efficient communication channels that take advantage of Indonesia's group-oriented culture will be used: namely, a mass media campaign and community mobilization. As radio soap operas in Nepal and television spots in Egypt have demonstrated, the mass media can model interactive family planning

consultations and change community perceptions of acceptable behavior with providers. ${ }^{46}$ Group educational sessions conducted by community workers also have the ability to harness the power of peer pressure to change behavior; their utility in reshaping client communication has been demonstrated in the U.S. ${ }^{47}$ The Smart Patient message will also continue to be disseminated in clinics, using revised and streamlined self-learning materials that do not require client literacy or the presence of an educator. The last element of the national intervention will be job aids and further training for providers so they respond accurately as well as warmly to client inquiries. 


\section{Conclusion}

This study has confirmed that educational interventions directed to family planning clients can help them become effective partners in their own care, assuming they meet with receptive providers. Communication interventions like Smart Patient complement and reinforce provider IPC/C training by giving clients the confidence and the skills to take advantage of increased opportunities for participation. Together, client and provider interventions can improve the quality of the client-provider interaction. 


\section{Footnote}

*The exchange rate at the time of the study was: US $\$ 1=10,000$ rupiah.

Increasing Client Participation in Family Planning Consultations: "Smart Patient" Coaching in Indoensia 26 


\section{References}

1. Frederickson LG and Bull PE, Evaluation of a patient education leaflet designed to improve communication in medical consultations, Patient Education and Counseling, 1995, 25:51-57; and McCann S and Weinman J, Empowering the patient in the consultation: a pilot study, Patient Education and Counseling, 1996, 27:227-234.

2. Kaplan SH, Greenfield S and Ware JW, Assessing the effect of the physician-patient interaction on the outcomes of chronic disease, Medical Care, 1989, 27(3 supplement): S110-127; Waitzkin H, Information giving in medical care, Journal of Health and Social Behaviors, 1985, 26: 81-101; and Young M and Klingle RS, Silent partners in medical care: a cross-cultural study of patient participation, Health Communication, 1996, $8(1): 29-53$.

3. Robinson EJ and Whitfield MJ, Improving the efficiency of patients' comprehension monitoring: a way of increasing patients' participation in general practice consultation, Social Science \& Medicine, 1985, 21(8):915-919; Socha McGee D and Cegala DJ, Patient communication skills training for improved communication competence in the primary care medical consultation, Journal of Applied Communication Research, 1998, 26:412-30; and Thompson SC, Nanni D and Schwankovsky L, Patient-oriented interventions to improve communication in a medical office visit, Health Psychology, 1990, 9(4):390-404.

4. Kaplan SH, Greenfield S and Ware JW, 1989, op. cit. (see reference 2); Brody D et al., Patient perception of involvement in medical care: relationship to illness attitudes and outcomes, Journal of General Internal Medicine, 1989, 4:506-511; Cegala DJ, Marinelli $\mathrm{T}$ and Post $\mathrm{D}$, The effects of patient communication skills training on compliance, Archives of Family Medicine, 2000, 9:57-64; Greenfield S, Kaplan S and Ware JE, Expanding patient involvement in care: effects on patient outcomes, Annals of Internal Medicine, 1985, 102:520-528; Greenfield S et al., Patients' participation in medical care: effects on blood sugar control and quality of life in diabetes, Journal of General Internal Medicine, 1988, 3:448-457; and van den Brink-Muinen A et al., The Eurocommunication study: An international comparative study in six European countries on doctor-patient communication in general practice. Utrecht, The Netherlands: NIVEL, 1999.

5. Upadhyay UD, Informed choice in family planning: helping people decide, Population Reports, 2001, Series J, No. 47; and Lipkin M. Physician-patient interaction in reproductive counseling, Obstetrics \& Gynecology, 1996, 88(3 supplement):31S-40S. 
6. Kim YM et al., Client participation and provider communication in family planning counseling: transcript analysis in Kenya, Health Communication, 1999, 11:1-19; Roter D, Patient participation in the patient-provider interaction: the effects of patient question asking on the quality of interaction, satisfaction and compliance, Health Education Monographs, 1977, 5(4):281-315; Roter D et al., The effects of a continuing medical education programme in interpersonal communication skills on doctor practice and patient satisfaction in Trinidad and Tobago, Medical Education, 1998;32:181-189; and Street RL, Information-giving in medical consultations: the influence of patients' communicative styles and personal characteristics, Social Science and Medicine, 1991, 32(5):541-48.

7. Greenfield S, Kaplan S and Ware JE, 1985, op. cit. (see reference 4); and Socha McGee D and Cegala DJ, 1998, op.cit. (see reference 3).

8. Barry CA et al., Patients' unvoiced agendas in general practice consultations: qualitative study, British Medical Journal, 2000, 320:1246-50; Britten N et al., Misunderstandings in prescribing decisions in general practice: qualitative study, British Medical Journal, 2000, 320:484-488; and DiMatteo MR, The physician-patient relationship: effects on the quality of health care, Clinical Obstetrics and Gynecology, 1994, 37(1):149-161.

9. DiMatteo MR, 1994, op.cit. (see reference 8).

10. Brody D et al., 1980, op. cit. (see reference 4); Street RL, 1991, op. cit. (see reference 6); Upadhyay UD, 2001, op. cit. (see reference 5).

11. Kim YM et al., Self-assessment and peer review: improving Indonesian service providers' communication with clients, International Family Planning Perspectives, 2000, 26(1):4-12; Magnis-Suseno F, Javanese Ethics and World-View: The Javanese Idea of the Good Life. Jakarta: Gramedia, 1987; and Young M and Klingle RS, 1996, op. cit. (see reference 2).

12. Kim YM et al., 2000, op. cit. (see reference 11).

13. Cegala DJ et al., The effects of patient communication skills training on patients' participation during medical interviews, Patient Education and Counseling, 2000, 41: 209-222; Frederickson LG and Bull PE, 1995, op. cit. (see reference 1); McCann S and Weinman J, 1996, op. cit. (see reference 1); Middleton JF, Asking patients to write lists: feasibility study, British Medical Journal, 1995, 311:34; Robinson EJ and Whitfield MJ, 1985, op. cit. (see reference 3); Tabak ER, Encouraging patient question-asking: a clinical trial, Patient Education and Counseling, 1988, 12:37-49; and Thompson SC, Nanni D and Schwankovsky L, 1990, op. cit. (see reference 3). 
14. Anderson LA, DeVellis BM and DeVellis RF, Effects of modeling on patient communication, satisfaction, and knowledge, Medical Care, 1987, 25(11):1044-1056; Street RL et al., Increasing patient involvement in choosing a treatment for early breast cancer, Cancer, 1995, 76(11):2275-2285.

15. Greenfield S, Kaplan S and Ware JE, 1985, op. cit. (see reference 4); Kaplan SH, Greenfield S and Ware JW, 1989, op. cit. (see reference 2); Roter D, 1977, op. cit. (see reference 6); and Socha McGee D and Cegala DJ, 1998, op.cit. (see reference 3).

16. Cegala D et al., 2000, op.cit. (see reference 13); and Fleissig A, Glasser B and Lloyd $\mathrm{M}$, Encouraging outpatients to make the most of their first hospital appointment: to what extent can a written prompt help patients get the information they want? Patient Education and Counseling, 1999, 38:69-79.

17. Middleton JF, 1995, op. cit. (see reference 13).

18. Tennstedt SL, Empowering older patients to communicate more effectively in the medical encounter, Clinics in Geriatric Medicine, 2000, 16(1):61-70.

19. Fleissig A, Glasser B and Lloyd M, 1999, op. cit. (see reference 16); Robinson EJ and Whitfield MJ, 1985, op. cit. (see reference 3); Tabak ER, 1988, op. cit. (see reference 13); and Thompson SC, Nanni D and Schwankovsky L, 1990, op. cit. (see reference 3).

20. Anderson LA and Sharpe PA, Improving patient and provider communication: a synthesis and review of communication interventions, Patient Education and Counseling, 1991, 17:99-134.

21. Anderson LA, DeVellis BM and DeVellis RF, 1987, op.cit. (see reference 14); Roter D, 1977, op. cit. (see reference 6); and Socha McGee D and Cegala DJ, 1998, op.cit. (see reference 3); and Thompson SC, Nanni D and Schwankovsky L, 1990, op. cit. (see reference 3 ).

22. Anderson LA, DeVellis BM and DeVellis RF, 1987, op.cit. (see reference 14); Cegala D et al., 2000, op.cit. (see reference 13); and Middleton JF, 1995, op. cit. (see reference 13).

23. Cegala D et al., 2000, op.cit. (see reference 13); Greenfield S, Kaplan S and Ware JE, 1985 , op. cit. (see reference 4); Greenfield S et al., 1988, op. cit. (see reference 4); and Kaplan SH, Greenfield S and Ware JW, 1989, op. cit. (see reference 2).

24. Robinson EJ and Whitfield MJ, 1985, op. cit. (see reference 3); and Socha McGee D and Cegala DJ, 1998, op.cit. (see reference 3).

25. Greenfield S, Kaplan S and Ware JE, 1985, op. cit. (see reference 4); Greenfield S et al., 1988, op. cit. (see reference 4); Kaplan SH, Greenfield S and Ware JW, 1989, op. cit. (see reference 2); and Tabak ER, 1988, op. cit. (see reference 13). 
26. Thompson SC, Nanni D and Schwankovsky L, 1990, op. cit. (see reference 3).

27 Kim YM et al., 2000, op. cit. (see reference 11); and Kim YM et al., Client communication behaviors with health care providers in Indonesia, Patient Education and Counseling, 2001, 45(1):59-68.

28. Kim YM et al., 2000, op. cit. (see reference 11).

29. Roter D, The Roter Interaction Analysis System (RIAS) Coding Manual. Baltimore: Johns Hopkins University School of Hygiene and Public Health, 1997.

30. Kim YM et al., 2000, op. cit. (see reference 11); and Kim YM et al., 2001, op. cit. (see reference 27).

31. Cegala D et al., 2000, op.cit. (see reference 13); and Socha McGee D and Cegala DJ, 1998, op.cit. (see reference 3);

32. Fleissig A, Glasser B and Lloyd M, 1999, op. cit. (see reference 16); and Roter DL, Patient question-asking in physician-patient interaction, Health Psychology, 1984, 3(5):395-409.

33. Anderson LA and Sharpe PA, 1991, op. cit. (see reference 20).

34. Young M and Klingle RS, 1996, op. cit. (see reference 2).

35. Fleissig A, Glasser B and Lloyd M, 1999, op. cit. (see reference 16), Thompson SC, Nanni D and Schwankovsky L, 1990, op. cit. (see reference 3).

36 Frederickson; Thompson SC, Nanni D and Schwankovsky L, 1990, op. cit. (see reference 3 ).

37. Robinson EJ and Whitfield MJ, 1985, op. cit. (see reference 3).

38. Kim YM et al., 2000, op. cit. (see reference 11);

39. White MK and Rucker L, A randomized controlled trial to affect the effect of physician and patient interventions to enhance physician-patient communication, presented at the Communication in Medicine Conference, Evanston, Illinois, July 1999.

40. Fleissig A, Glasser B and Lloyd M, 1999, op. cit. (see reference 16); and Tanner G and Myers P, Shared agendas improve communication, British Medical Journal Electronic Letters, 4 February 2000, available online at www.bmj.com/cgi/eletters/320/7230/314/a (accessed 4/25/01).

41. Middleton JF, 1995, op. cit. (see reference 13). 
42. Anderson LA, DeVellis BM and DeVellis RF, 1987, op.cit. (see reference 14); Frederickson, Socha McGee D and Cegala DJ, 1998, op.cit. (see reference 3);

43. Robinson EJ and Whitfield MJ, 1985, op. cit. (see reference 3); and Socha McGee D and Cegala DJ, 1998, op.cit. (see reference 3);

44. Street RL, 1991, op. cit. (see reference 6); Waitzkin H, 1985, op. cit. (see reference 2); and Waitzkin $\mathrm{H}$ et al., Patient-doctor communication in cross-national perspective: a study in Mexico, Medical Care, 1996, 34(7):641-671.

45. Young M and Klingle RS, 1996, op. cit. (see reference 2).

46. Kols AJ and Sherman JE, Family planning programs: improving quality, Population Reports, 1998, Series J, No. 47; and Storey D et al., Impact of the Integrated Radio Communication Project in Nepal, 1994-1997, Journal of Health Communication, 1999, 4(4):271-294.

47. Tennstedt SL, 2000, op. cit. (see reference 18) 
Table 1. Percentage distribution of client characteristics by intervention and control group

\begin{tabular}{|c|c|c|c|}
\hline Client characteristics & $\begin{array}{l}\text { Control } \\
(n=384)\end{array}$ & $\begin{array}{c}\text { Intervention } \\
(n=384)\end{array}$ & $\begin{array}{l}\text { TOTAL } \\
(n=768)\end{array}$ \\
\hline \multicolumn{4}{|l|}{ Age } \\
\hline $17-24$ & 20.1 & 20.2 & 20.1 \\
\hline $25-34$ & 53.1 & 51.1 & 52.1 \\
\hline $35-50$ & 26.8 & 28.8 & 27.8 \\
\hline \multicolumn{4}{|l|}{ Number of children } \\
\hline $0-1$ & 31.0 & 30.2 & 30.6 \\
\hline 2 & 39.6 & 40.6 & 40.1 \\
\hline 3 or more & 29.4 & 29.2 & 29.3 \\
\hline \multicolumn{4}{|l|}{ Education } \\
\hline Elementary or less & 45.3 & 42.5 & 43.9 \\
\hline Completed Junior High & 29.9 & 30.2 & 29.6 \\
\hline Senior High School and & 25.8 & 27.3 & 26.6 \\
\hline \multicolumn{4}{|c|}{ Monthly expenses per family member* } \\
\hline $4,000-59,000 R p$ & 47.1 & 49.0 & 48.0 \\
\hline $60,000-375,000 \mathrm{Rp}$ & 52.9 & 51.0 & 52.0 \\
\hline \multicolumn{4}{|l|}{ Reason for visit } \\
\hline New client, never user & 12.2 & 14.3 & 13.3 \\
\hline New client, restarting & 21.4 & 19.3 & 20.3 \\
\hline Cont. client, no problems & 15.4 & 14.9 & 15.1 \\
\hline Cont. client, has problems & 51.0 & 51.6 & 51.3 \\
\hline \multicolumn{4}{|l|}{ Contraceptive method } \\
\hline Pill ${ }^{*}$ & 22.4 & 19.1 & 20.7 \\
\hline Injectable & 43.5 & 47.0 & 45.3 \\
\hline IUD & 20.8 & 22.2 & 21.5 \\
\hline Implant & 10.8 & 10.7 & 10.8 \\
\hline Other & 2.4 & 1.0 & 1.7 \\
\hline \multicolumn{4}{|l|}{ Assertiveness } \\
\hline Low $(<15)$ & 11.2 & 9.6 & 10.4 \\
\hline Medium low (15-19) & 40.1 & 37.0 & 38.5 \\
\hline Medium high (20-24) & 35.2 & 41.2 & 38.2 \\
\hline $\operatorname{High}(25+)$ & 13.5 & 12.2 & 12.9 \\
\hline
\end{tabular}

* The exchange rate at the time of the study was: US $\$ 1=10,000$ rupiah 
Table 2. Percent of clients who have experienced psychosocial barriers to communicating with midwife in the past $(n=768)$

\begin{tabular}{lccc}
\hline & Often & Sometimes & Never \\
\hline Forget to ask & 19.6 & 58.3 & 22.0 \\
Find it hard to think of questions to ask & 19.3 & 46.5 & 34.1 \\
Worry my questions are not important & 25.5 & 32.8 & 41.5 \\
Don't want to take up midwife's time & 22.4 & 35.3 & 42.2 \\
Think midwife will not be interested & 22.1 & 34.9 & 42.8 \\
Afraid midwife will ignore my concern & 25.0 & 30.2 & 44.7 \\
Feel it is not my place to ask & 18.3 & 35.7 & 46.0 \\
Find it hard to ask for repeat explanation & 26.2 & 26.3 & 47.4 \\
\hline
\end{tabular}




\begin{tabular}{|c|c|c|c|c|}
\hline & $\begin{array}{l}\text { Control } \\
(n=384)\end{array}$ & $\begin{array}{c}\text { Intervention } \\
(n=384)\end{array}$ & Differential & $p$-value \\
\hline $\begin{array}{l}\text { Age } \\
17-24 \\
25-34 \\
35-50\end{array}$ & $\begin{array}{r}14.3 \\
12.1 \\
9.4 \\
\end{array}$ & $\begin{array}{l}11.7 \\
15.3 \\
16.5\end{array}$ & $\begin{array}{r}-2.5 \\
+3.2 \\
+7.1\end{array}$ & $\begin{array}{l}.2827 \\
.0178 \\
.0002\end{array}$ \\
\hline $\begin{array}{l}\text { Education } \\
\text { Elementary or less } \\
\text { Junior high } \\
\text { Senior high plus }\end{array}$ & $\begin{array}{l}10.7 \\
13.0 \\
12.4\end{array}$ & $\begin{array}{l}13.4 \\
14.9 \\
16.9\end{array}$ & $\begin{array}{l}+2.7 \\
+1.9 \\
+4.5\end{array}$ & $\begin{array}{l}.0466 \\
.4084 \\
.0092\end{array}$ \\
\hline $\begin{array}{l}\text { Monthly expenses per family } \\
\text { member } \\
\text { Low (less than } 60,000 \mathrm{rp}) \\
\text { High }(60,000 \mathrm{rp}+)\end{array}$ & $\begin{array}{l}12.6 \\
11.2\end{array}$ & $\begin{array}{l}13.2 \\
16.4\end{array}$ & $\begin{array}{l}+0.6 \\
+5.2\end{array}$ & $\begin{array}{l}.6766 \\
.0002\end{array}$ \\
\hline $\begin{array}{l}\text { Assertiveness } \\
\text { Low }(<20) \\
\text { High }(20+)\end{array}$ & $\begin{array}{l}10.8 \\
12.9\end{array}$ & $\begin{array}{l}14.2 \\
15.4\end{array}$ & $\begin{array}{l}+3.4 \\
+3.5\end{array}$ & $\begin{array}{l}.0165 \\
.0818\end{array}$ \\
\hline $\begin{array}{l}\text { Client type } \\
\text { New, never user } \\
\text { New client, restarting } \\
\text { method } \\
\text { Cont. client, no problems } \\
\text { Cont. client, has problems }\end{array}$ & $\begin{array}{r}13.2 \\
12.1 \\
9.4 \\
12.1\end{array}$ & $\begin{array}{l}15.7 \\
16.2 \\
13.4 \\
14.5\end{array}$ & $\begin{array}{l}+2.5 \\
+4.1 \\
+4.0 \\
+2.4\end{array}$ & $\begin{array}{l}.3515 \\
.0373 \\
.0453 \\
.1228\end{array}$ \\
\hline
\end{tabular}


Figure 1. Frequency of client participation: Smart patient intervention vs. control

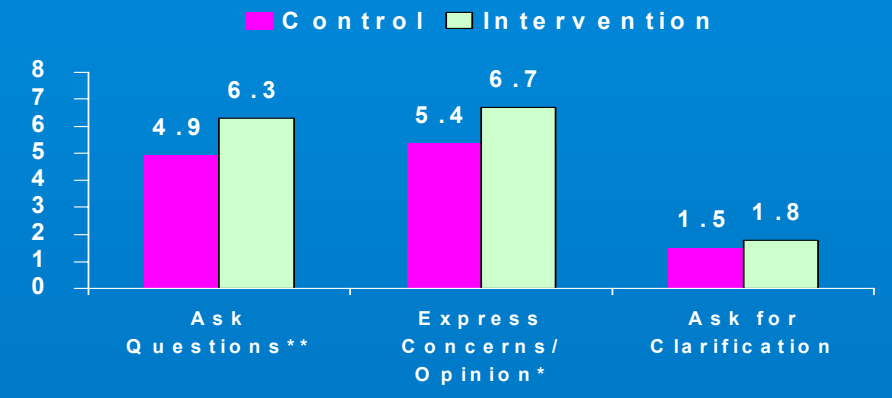

Figure 2. Frequency of client questions: $\mathrm{Smart}$ patient intervention vs, control

Control $\square$ Intervention

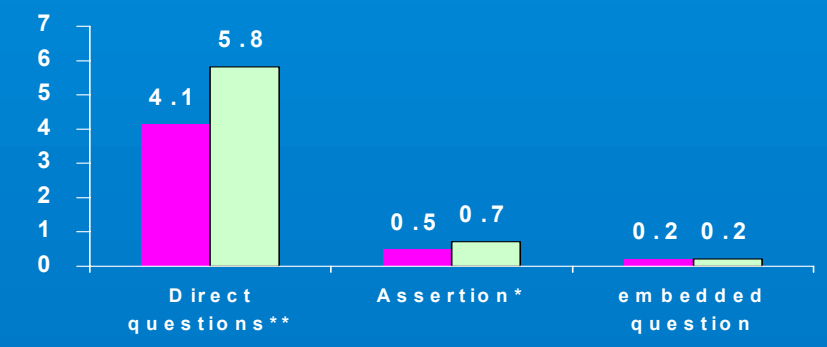

